\title{
Chronic Nephropathies in the Internal Medicine Department of the Sylvanus Olympio University Hospital
}

\section{Agbeko Kodjo Djagadou ${ }^{1}$, Toyi Tchamdja², Abdou-Bakari Tchala1, Yawovi Mawufemo Tsevi ${ }^{3}$, Abago Balaka', Awalou Mohaman Djibril ${ }^{1}$}

${ }^{1}$ Department of Internal Medicine, Sylvanus Olympio University Hospital, University of Lomé, Lomé, Togo

${ }^{2}$ Department of Internal Medicine, Kara University Hospital, University of Kara, Kara, Togo

${ }^{3}$ Department of Nephrology and Hemodialysis, Sylvanus Olympio University Hospital, University of Lomé, Lomé, Togo

Email: ^djagkodj11@gmail.com

How to cite this paper: Djagadou, A.K., Tchamdja, T., Tchala, A.-B., Tsevi, Y.M., Balaka, A. and Djibril, A.M. (2021) Chronic Nephropathies in the Internal Medicine Department of the Sylvanus Olympio University Hospital. Open Journal of Internal Medicine, 11, 140-150.

https://doi.org/10.4236/ojim.2021.113011

Received: July 2, 2021

Accepted: September 4, 2021

Published: September 7, 2021

Copyright $\odot 2021$ by author(s) and Scientific Research Publishing Inc. This work is licensed under the Creative Commons Attribution International License (CC BY 4.0).

http://creativecommons.org/licenses/by/4.0/

(c) (i) Open Access

\begin{abstract}
Introduction: The chronic nephropathies constitute a real global public health concern due to the constant increase in the prevalence estimated between $10 \%$ and $15 \%$. In Sub-Saharan Africa, this prevalence has been estimated at $13.9 \%$. This study will allow knowing the epidemiological, clinical, paraclinical and etiological aspects of chronic kidney disease in the internal medicine department of CHU-SO Lomé. Method: This was a cross-sectional, retrospective and descriptive study. It concerned all the patients suffering from a chronic kidney disease, hospitalized between the 1st of January 2014 and the 31st of December 2018, for a duration of 5 years. Results: During our study, 330 cases of chronic nephropathy were identified. The prevalence of chronic kidney disease was $8.3 \%$ of admissions. The mean age of the patients was 46.3 years with extremes of 19 and 86 years and a sex ratio of 1.32. A low socioeconomic level of patients was observed in $63.9 \%$ with an urban origin in $69.7 \%$. The main risk factors for renal impairment were hypertension (55.2\%), diabetes mellitus (29.1\%), obesity (20.6\%), use of nephrotoxic products (19.4\%), HIV infection (17\%) and smoking (16.1\%). The causes were dominated by nephroangiosclerosis (33.3\%), followed by diabetic nephropathy (25.5\%) and HIV-associated nephropathy (17\%). Chronic renal failure was present in $95.8 \%$ of cases and was end stage in $69.7 \%$ of cases. Anemia was the main complication during the evolution of chronic kidney disease (98.2\%). Mortality was 57.3\% during hospitalization. Conclusion: Chronic kidney disease is a fairly common reason for hospitalization in the internal medicine department. Emphasis should therefore be placed on preventive measures for hypertension, diabetes and HIV.
\end{abstract}




\section{Keywords}

Chronic Kidney Disease, Profile, CHU, Lomé (Togo)

\section{Introduction}

Chronic nephropathies (CNP) are defined by the presence of markers of renal damage (structural or functional) and/or a decrease in estimated glomerular filtration rate $(\mathrm{eGFR})<60 \mathrm{ml} / \mathrm{min} / 1.73 \mathrm{~m}^{2}$ [1] for more than three months. They constitute a real global public health concern due to the constant increase in the prevalence estimated between $10 \%$ and 15\% [2] [3]. In Sub-Saharan Africa, this prevalence has been estimated at $13.9 \%$ [4]. Projections for 2030 predict that more than $70 \%$ of the world's population with end-stage renal disease (ESRD) will end up in developing countries, including most of the countries of Sub-Saharan Africa [4]. The cost of medical care for patients with CNP is very high according to the International Society of Nephrology (ISN) [5]. In Togo, the average global cost of care for a non-dialyzed CKD patient, hospitalized at the Sylvanus Olympio University Hospital (CHU-SO) in Lomé amounted to 199.289.4 FCFA i.e. 5.7 times the Guaranteed Minimum Interprofessional Wage (SMIG) [6]. When the patient is on dialysis, the average annual cost including hemodialysis and medical expenses was 11,422,490.7 FCFA [7] and could be higher in private clinics.

Faced with this important medico-economic issue, the prevention of CNP becomes a necessity and implies a better knowledge of the profile of patients suffering from CNP. This work was carried out to describe the global profile of chronic nephropathies. The specific objectives were to:

- Describe the epidemiological aspects of chronic nephropathies.

- Describe the clinical and paraclinical aspects of chronic nephropathies.

- Describe the pathologies associated with chronic nephropathies.

\section{Framework and Method}

The internal medicine department of the Sylvanus Olympio University Hospital (CHU-SO) served as the study setting. This was a descriptive and cross-sectional study with retrospective data collection. It focused on the records of patients suffering from chronic nephropathy, hospitalized in the internal medicine department of the CHU-SO from January 1, 2016 to December 31, 2021, i.e. a period of 5 years. We extracted deidentified data from the unit registry.

Were included in this study, all patients aged 16 years and over, hospitalized during the study period in the internal medicine department, having presented a chronic nephropathy defined by the presence for more than 3 months, of markers of renal damage that were:

- morphological abnormalities of the renal parenchyma on ultrasound (small 
kidney $<10 \mathrm{~cm}$, large kidney $>120 \mathrm{~cm}$, loss of differentiation) and/or

- biological abnormalities (proteinuria, albuminuria, hematuria, leukocyturia, and/or decrease in glomerular filtration rate (GFR) below $60 \mathrm{~mL} / \mathrm{min} / 1.73 \mathrm{~m}^{2}$ )

Glomerular filtration rate is estimated by calculating serum creatinine clearance according to the simplified MDRD (Modified Diet in Renal Diseases) [1].

All patients with chronic nephropathy receiving hemodialysis or having already undergone transplantation before admission to the department were excluded.

In the absence of a renal puncture biopsy, the following semiological classification was adopted to identify the type of initial nephropathy:

- Chronic glomerular nephropathies (CGN): they were defined by proteinuria $>1$ g/24 hours, microscopic or macroscopic hematuria, more or less important hydrosodic retention (edemas) preceding arterial hypertension (HTA) and small regular symmetrical kidneys.

- Chronic tubulointerstitial nephropathies (CTIN): they were defined by proteinuria $<1 \mathrm{~g} / 24 \mathrm{~h}$, non-glomerular type, leukocyturia, tubular abnormalities (hyperchloremic acidosis, sodium loss), often absent hypertension and small, irregular, bumpy, sometimes asymmetrical kidneys with calicar abnormalities in case of chronic pyelonephritis

- HIV-associated nephropathy or HIVAN: the clinical picture usually occurs in a context of severe HIV-related immunosuppression (CD4 $<200 / \mathrm{mm}^{3}$, and/or high viral load). It combines glomerular-type proteinuria with rapidly progressing renal failure, but with little or no edema. The kidneys are hyperechoic and increased in size on ultrasound.

- Diabetic nephropathy (DN): it is defined by the presence in a long-term diabetic of microalbuminuria between 150 and $300 \mathrm{mg} / 24 \mathrm{~h}$ associated with an inactive urinary sediment and diabetic retinopathy.

- Chronic vascular nephropathies (CVN): defined by proteinuria $<1 \mathrm{~g} / 24 \mathrm{~h}$, hematuria most often irregular, constant hypertension often old and main symptom and small kidneys often irregular. Atherosclerotic disease or stenosis of the renal arteries may be associated with it on echodoppler.

- Nephro-angiosclerosis (NAS) is defined by the presence of CKD in a longterm hypertensive patient, associated with albuminuria $<500 \mathrm{mg} / 24 \mathrm{~h}$, inactive urinary sediment, hypertensive retinopathy and left ventricular hypertrophy.

- Hereditary nephropathies (NH): these essentially group together autosomal dominant polycystic kidney disease.

- Unclassifiable chronic nephropathies (UCN) are those whose semiology does not allow them to be classified in one of the groups.

- Chronic kidney disease (CKD) defined by: Renal history: old creatinemia > 3 months and high, Biological arguments (anemia, hypocalcemia, hyperphosphatemia), radiological arguments (kidney size $<100 \mathrm{~mm}$ ), and/or a GFR $<60 \mathrm{~mL} / \mathrm{min} / 1.73 \mathrm{~m}^{2}$ (according to MDRD) 


\section{Study Techniques}

The medical records carried out by the doctors were used to collect the data collected on a survey form.

- Sociodemographic characteristics: age, gender, profession, place of origin, socioeconomic group.

- Associated factors: current or past smoking or alcohol use; lack of physical activity; family history of diabetes mellitus, hypertension and kidney disease; personal history of hypertension, diabetes mellitus, heart disease, dyslipidemia, kidney disease, gout, sickle cell disease, HIV infection, systemic disease; notion of taking non-steroidal anti-inflammatory drugs (NSAIDs) or other nephrotoxic products, traditional products; notion of repeated urinary tract infection.

- Socioeconomic level (SEL) was subdivided into three groups according to the patients' supposed income: high SEL when the income is estimated above 150,000 FCFA per month, average SEL when the income is between 35,000 and 150,000 FCFA per month, low SEL when the income is less than or equal to 35,000 FCFA per month i.e. the minimum wage.

- Social coverage through either private or public health insurance (National Institute of Health Insurance)

- Clinical parameters: Hypertension (HTA) defined by an SBP $\geq 140 \mathrm{~mm} \mathrm{Hg}$ and/or a DBP $\geq 90 \mathrm{mmHg}$; diabetes mellitus defined by fasting glycemia $\geq$ $126 \mathrm{mg} / \mathrm{dl}$; body mass index (BMI) defined by weight/height squared $\left(\mathrm{kg} / \mathrm{m}^{2}\right)$ : BMI $\geq 30$ (obesity); BMI between 25 - 29.9 (overweight); BMI between 18.5 24.9 (normal); BMI < 18.5 (thinness); Chronic kidney disease was classified according to KDIGO 2012 (Table 1) [1].

\section{- Data and Statistical analysis}

All data were entered into a data entry mask developed in Epi data version 3.1 software and then analyzed using IBM SPSS Statistics 20 statistical software.

Categorical data were expressed as percentages. The chi-square test was used to compare proportions. A p-value $<5 \%$ was considered statistically significant.

- Creatinine was measured using the Jaffé colorimetric method.

- Urinary sediment is sought in fresh morning urine and proteinuria by collecting 24-hour urine.

Table 1. Classification of chronic kidney disease according to KDIGO 2012.

\begin{tabular}{ccc}
\hline Stage & Description & GFR $\left(\mathrm{ml} / \mathrm{min} / 1.73 \mathrm{~m}^{2}\right)$ \\
\hline 1 & Renal impairment with normal or increased GFR & $>90$ \\
2 & Renal impairment with slightly reduced GFR & $60-90$ \\
3 & Moderate kidney disease & $30-60$ \\
4 & Severe kidney disease & $15-30$ \\
5 & End-stage kidney disease & $<15$ \\
\hline
\end{tabular}


- The following ultrasound classification has been adopted for the renal echostructure: stage 0 or normal kidney for a hypoechoic renal cortex relative to that of the liver; stage I for an isoechoic renal cortex relative to the liver; stage II for a renal cortex that is hyperechoic relative to the liver but hypoechoic relative to the renal sinus with preservation of cortico-medullary differentiation; and stage III for a hyperechoic renal cortex relative to the liver and isoechoic relative to the renal sinus with disappearance of cortico-medullary differentiation.

\section{Results}

\subsection{Socio-Demographic Data}

During our study, 3988 patients were hospitalized in the internal medicine department among whom we identified 330 cases of chronic nephropathy according to the predefined criteria. The prevalence of CNP in the department was $8.3 \%$ of admissions. There were 188 men i.e. $57 \%$ and 142 women i.e. $43 \%$ with a sex ratio $(\mathrm{M} / \mathrm{F})$ of 1.32 . The mean age was $46.3 \pm 14.4$ years with extremes of 19 and 86 years. The 35 - 44 age group was the most affected.

The socio-economic level (SEL) in $63.9 \%$ of cases is low with a precarious financial situation.

Only $8 \%$ of the patients are senior executives. The majority of patients, i.e. $81 \%$, did not have health insurance coverage. Among the patients who had health insurance, $13 \%$ were insured with INAM, the public insurance company. The majority of our patients, i.e. $69.7 \%$, lived in urban areas.

\subsection{Clinical Data}

\section{Associated Clinical Etiological Factors}

Known hypertension in $55.2 \%$ of patients was the main risk factor, followed for diabetes in $29.1 \%$ of cases. The distribution of patients according to the associated factors is shown in Table 2.

Table 2. Distribution of patients according to associated factors.

\begin{tabular}{ccccc}
\hline HTA & Male & Female & Total & $\%$ \\
Alcohol intake & 110 & 72 & 182 & 55.2 \\
Diabetes mellitus & 96 & 14 & 110 & 33.3 \\
Obesity & 65 & 31 & 96 & 29.1 \\
Use of medicinal plants & 50 & 46 & 96 & 29.1 \\
HIV & 26 & 38 & 64 & 19.4 \\
Tobacco exhibition & 22 & 34 & 56 & 17 \\
Repeated urinary tract infections & 53 & 0 & 53 & 16.1 \\
Chronic viral hepatitis & 12 & 6 & 18 & 5.2 \\
Use & 13 & 5 & 18 & 5.5 \\
\hline
\end{tabular}

HTA = High Blood pressure, HIV = Human Immuno-depression Virus. 


\subsection{Paraclinical Data}

\subsubsection{Renal Biological Data}

The distribution of mean and extreme values of renal data can be found in Table 3 .

Cytobacteriological urine test (CBEU) was performed in 110 patients. It revealed a urinary tract infection in $16.4 \%$ of cases (18/110 examinations) of which 6 cases were responsible for NICT. The germs found were: Klebsiella pneumoniae 8 cases (44.4\%), Escherichia coli 2 cases (11.1\%), Enterobacter aerogenes 2 cases (11.1\%), Pseudomonas aeroginosa 2 cases (11.1\%), Staphylococcus aureus 2 cases $(11.1 \%)$.

The study of the different fractions had shown a predominance of: hypercholesterolemia $>2 \mathrm{~g} / \mathrm{l}$ in $36.8 \%$, hypertriglyceridemia $>1.50 \mathrm{~g} / \mathrm{l}$ in $48.1 \%$.

\subsubsection{Type of Chronic Nephropathies}

We observed a predominance of glomerular nephropathies in 152 cases (46.1\%), followed by chronic vascular nephropathies 110 cases (33.3\%), diabetic nephropathies 36 cases $(10.9 \%)$ and chronic tubulointerstitial nephropathies 32 cases $(9.6 \%)$

\subsubsection{Stages of Chronic Kidney Disease}

The majority of patients had end-stage CKD, i.e. $69.7 \%$. Figure 1 shows the distribution of patients according to CKD stages

\subsubsection{Causal Pathologies of CNPs}

Unbalanced hypertension (33.3\%), unbalanced diabetes (25.5\%) and HIV (17\%) were the main probable causes of CNPs. The toxic origin was related to the use of medicinal plants and the other origins included $8 \mathrm{HBV}$ and $4 \mathrm{HCV}$. The cases of obstructive uropathy were due to 6 prostate adenocarcinomas and 2 cervical neoplasia.

\subsection{Evolving Data}

\subsubsection{Main Complications of CNP}

Anemia is the main complication of CNP in $98.2 \%$. Table 4 shows the distribution of major complications of CNPs.

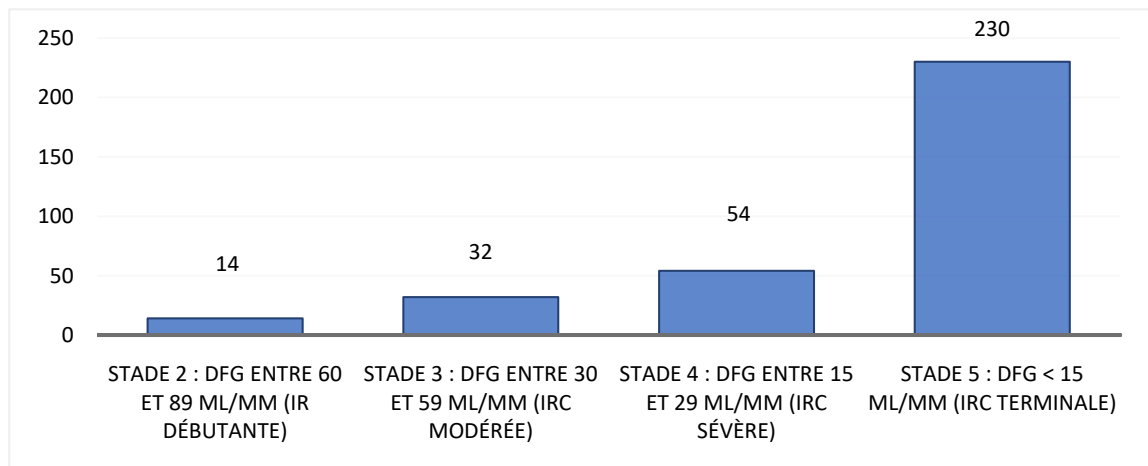

Figure 1. Distribution of patients according to CKD stage. $\mathrm{X}$-axis: Number of CKD, Y-axis: Stage of KCD. 
Table 3. Mean and extreme values of nitrogenous waste.

\begin{tabular}{ccccc}
\hline & Average & Standard deviation & Minimum & Maximum \\
\hline Uremia $(\mathrm{g} / \mathrm{l})$ & 1.85 & 1.07 & 0.17 & 4.78 \\
Creatinemia $(\mathrm{mg} / \mathrm{l})$ & 130.33 & 104.30 & 12.0 & 510.0 \\
Uricemia $(\mathrm{mg} / \mathrm{l})$ & 97.21 & 32.73 & 15.0 & 176.0 \\
24 h proteinuria $(\mathrm{g})$ & 1.7 & 1.6 & 0.4 & 7.9 \\
\hline
\end{tabular}

Table 4. Distribution of patients according to the main complications of CNP.

\begin{tabular}{ccc}
\hline & Effective & $\%$ \\
\hline Anemia & 324 & 98.2 \\
HTA & 220 & 82.4 \\
APO $^{*}$ & 116 & 35.2 \\
Hematemesis & 40 & 12.2 \\
Coma & 34 & 10.3 \\
Phospho-calcium disorder & 217 & 80.1 \\
\hline
\end{tabular}

*APO: Acute Pulmonary Oedema.

\subsubsection{Length of Hospitalization}

The mean hospital stay was $15 \pm 10.8$ days, with extreme values of 2 and 67 days. This value of 67 days corresponds to the length of hospitalization of a patient with end-stage HIV-related CNP associated with nephrotic syndrome and a profound deterioration in general condition.

\subsubsection{Overall Mortality}

Of the CNP patients with CKD requiring hemodialysis, only 56 (24.3\%) had sufficient financial resources to access it.

One hundred and eighty-nine patients died during hospitalization, i.e. a mortality rate of $57.3 \%$. The average age among the deceased was $46.8 \pm 14.2$ years. Anemia was the main cause of death in our series followed by APO 43 cases (22.7\%) and severe sepsis 39 cases (20.6\%).

\section{Discussion}

\subsection{Limitation of Study}

This study suffered from the lack of renal biopsy which is important to improve the classification of the chronic nephropathies.

\subsection{Sociodemographic Aspect}

The mean age was $46.3 \pm 14.4$ years with a peak in the age range 35 - 44 years i.e. $31.5 \%$. This is similar to the results obtained in a meta-analysis published in The Lancet in 2014, where the most represented age range of patients from 13 subSaharan African countries, carriers of CNP, was 35 to 46 years [5]. This can be 
explained by the fact that this is the socially active population category that is easily exposed to certain environmental factors such as the use of alcohol, tobacco as well as medicinal plants that are sometimes nephrotoxic. Hypertension, one of the main causes of the disease, is also a factor affecting this category of the population due to social stress. This average age is lower than those obtained in developed countries where most patients are over 60 years old [2] [3]. This discrepancy between African and Western countries could be explained on the one hand by the young age of the African population and on the other hand by the greater accessibility to healthcare in industrialized countries and the aging of the Western population.

\subsection{Aspect of Associated Factors}

The antecedents were dominated by hypertension (55.2\%), alcoholism (33.3\%), diabetes mellitus (29.1\%), obesity (29.1\%), use of medicinal plants (19.4\%), HIV infection (17\%) and smoking (16.1\%). These antecedents are known to be important factors in the occurrence or worsening of CNP. Unbalanced hypertension and diabetes mellitus are one of the main causes of CKD in West Africa, ranging from $25 \%$ in Senegal to $29.8 \%$ in Nigeria, $48.7 \%$ where it is the cause of end-stage renal failure in $21 \%$ of patients [7]. Obesity has been identified as a risk factor for hypertension, diabetes and the occurrence of kidney disease [8]. Alcohol and tobacco consumption were significantly more common in men ( $\mathrm{p}<$ 0.001). A study conducted in patients with chronic nephropathy showed that GFR declined twice as fast in smokers as in non-smokers [9]. Another preventable risk factor for CNP is the use of herbal remedies, which was found in $19.4 \%$ of cases.

At this stage of observation, histopathological and toxicological studies are recommended to establish the causal relationship and the specific components of the incriminating products. HIV infection was reported in $17 \%$ in our study. As in a previous study, Sabi et al. [10] found a rate of $15.3 \%$ of patients infected with the HIV virus against a prevalence rate among the sexually active population (15 to 49 years) estimated at $3.2 \%$ in 2005 according to the United Nations Development Program (UNDP) in Togo. HIV is known to cause glomerular nephropathy, the typical HIVAN expression of which is histologically diagnosed [9]. Due to technical limitations, renal puncture biopsy was not performed. This remains a major challenge.

\subsection{Etiological Aspect of Chronic Nephropathies}

The etiological research of CNP constitutes a difficult stage of the management in our regions, renal biopsy being rarely performed as well as immunological assessments. This difficulty could largely explain the non-negligible rate of undetermined causes of CNP reported in $10.9 \%$ in our study.

In our series, probable causes were dominated by nephro-angiosclerosis (33.3\%), followed by diabetic nephropathy (25.5\%) and HIV-associated nephropathy (17\%). 
The same observation is made in most African studies where the known causes are by far dominated by nephro-angiosclerosis (NAS) with rates varying between $25 \%$ and $62.1 \%$ [10] [11] [12] [13].

On the contrary, Benja in Madagascar [14] and Bah in Guinea [15] had noted a predominance of chronic glomerulonephritis in $36.6 \%$ and $37.8 \%$ respectively, followed by NAS in $32.44 \%$ and $31.2 \%$ of cases. In developed countries, about $50 \%$ of severe kidney disease is the result of diabetes followed by hypertension [6].

\subsection{Stages of Chronic Nephropathy}

The majority (69.7\%) of our patients had chronic end stage nephropathy. Our result is similar to that of Benja [14] in Madagascar who found $75.31 \%$ of patients who were in the end-stage. The same observation was made by Naiker [7] who found more than $70 \%$ of end-stage CNP cases in most Sub-Saharan African countries. These data contrast with those of developed countries [2] [3] [16] where the majority of patients are seen before stage 3 . This late presentation of $\mathrm{CNP}$ in our series would be due to the poor screening policy and insufficient education on CNP; all this based on the low socioeconomic level and the lack of universal health insurance. This results in an inadequacy of the therapeutic management. Indeed, due to lack of financial means, $75.7 \%$ of the patients could not benefit from a replacement therapy (hemodialysis or kidney transplant). The high hospital mortality during our study (57.3\%) is therefore due to the absence of adequate treatment, as in Côte d'Ivoire (54\%) [17] and in Guinea Conakry $20.6 \%[15]$.

\section{Conclusion}

Chronic nephropathy is a real global public health concern, and its prevention requires a better knowledge of the profile of patients suffering from it. At the Sylvanus Olympio University Hospital, they represent $8.3 \%$ of admissions to the internal medicine department. They concerned young adults of low socioeconomic level seen in the majority of cases at the end stage of the disease requiring supplementary treatment. The main etiological factors are hypertension, diabetes mellitus and HIV. The high mortality was related to the lack of access to adequate care in the majority of cases. It is essential to focus on preventive measures, early detection and adequate treatment of risk factors for CNP.

\section{Conflicts of Interest}

The authors declare no conflicts of interest regarding the publication of this paper.

\section{References}

[1] Levey, A.S., de Jong, P.E., Coresh, J., Nahas, M.E.L., Astor, B.C., Matsushita, K., et al. (2011) The Definition, Classification, and Prognosis of Chronic Kidney Disease: 
A KDIGO Controversies Conference Report. Kidney International, 80, 17-28. https://doi.org/10.1038/ki.2010.483

[2] Chadban, S.J., Briganti, E.M., Kerr, P.G., Dunstan, D.W., Welborn, T.A., Zimmet, P.Z., et al. (2003) Prevalence of Kidney Damage Australian Adults: The AusDiab Kidney Study. Journal of American Society of Nephrology, 14, S131-S138. https://doi.org/10.1097/01.ASN.0000070152.11927.4A

[3] Stanifer, J.W., Jing, B., Tolan, S., Helmke, N., Mukerjee, R., Naicker, S., et al. (2014) The Epidemiology of Chronic Kidney Disease in Sub-Saharan Africa: A Systematic Review and Meta-Analysis. Lancet Global Health, 2, e174-e181. https://doi.org/10.1016/S2214-109X(14)70002-6

[4] Sabi, K.A., Noto-Kadou-Kaza, B., et al. (2017) Coût direct de la prise en charge de l'insuffisance rénale chronique non dialyse au Togo. Revue scientifique du Tchad, 1.

[5] Djagadou, K.A., Tchamdja, T., Némi, K.D., Djalogue, L., Balaka, A. and Djibril, M.A. (2019) Coût direct de la prise en charge des patients en insuffisance rénale chronique au centre hospitalier universitaire sylvanus olympio. Advance Research Journal of Multidisciplinary Discoveries, 33, 18-20.

[6] Bah, A.O., et al. (2014) Morbidité et mortalité hospitalières dues à l'insuffisance rénale chronique dans un pays dont l'accès à la dialyse est limité. Néphrologie \& Thérapeutique, 10, 394.

[7] Sabi, K.A., Gnionsahe, D.A. and Amedegnato, D. (2011) Chronic Kidney Failure in Togo: Clinical, Laboratory, and Etiological Aspects. Médecine Trop Rev Corps Santé Colon, 71, 74-76.

[8] National Kidney Foundation (2002) K/DOQI Clinical Practice Guidelines for Chronic Kidney Disease: Evaluation, Classification, and Stratification. American Journal of Kidney Diseases, 39, S1-266.

[9] Couser, W.G., Remuzzi, G., Mendis, S. and Tonelli, M. (2011) The Contribution of Chronic Kidney Disease to the Global Burden of Major Noncommunicable Diseases. Kidney International, 80, 1258-1270. https://doi.org/10.1038/ki.2011.368

[10] Naicker, S. (2013) End-Stage Renal Disease in Sub Saharan Africa. Kidney International Supplements, 3, 161-163. https://doi.org/10.1038/kisup.2013.4

[11] Chinar, A. (2015) Épidémiologie de l'insuffisance rénale chronique terminale à la daïra de Batna, Algérie. Néphrologie \& Thérapeutique, 11, 435.

https://doi.org/10.1016/j.nephro.2015.07.212

[12] Fouda, H., Nono, A., Kaze, F., Halle, M.-P., Mahamat, M. and Ashuntantang, G. (2017) Épidémiologie de la Maladie Rénale Chronique à l'Hôpital Général de Douala: Étude Comparative entre Hommes et Femmes. Health Sciences and Disease, 18, 35-39.

[13] Osafo, C., Mate-Kole, M., Affram, K. and Adu, D. (2011) Prevalence of Chronic Kidney Disease in Hypertensive Patients in Ghana. Renal Failure, 33, 388-392. https://doi.org/10.3109/0886022X.2011.565140

[14] OMS (2016) Profil sanitaire du Togo. https://www.who.int/countries/tgo/fr

[15] Ramilitiana, B., Ranivoharisoa, E.M., Dodo, M., Razafimandimby, E. and Randriamarotia, W.F. (2016) A Retrospective Study on the Incidence of Chronic Renal Failure in the Department of Internal Medicine and Nephrology at University Hospital of Antananarivo. The Pan African Medical Journal, 23, Article No. 141.

[16] Chen, W., Chen, W., Wang, H., Dong, X., Liu, Q., Mao, H., et al. (2009) Prevalence and Risk Factors Associated with Chronic Kidney Disease in an Adult Population from Southern China. Nephrology Dialysis Transplantation, 24, 1205-1212. 
https://doi.org/10.1093/ndt/gfn604

[17] Ouattara, B., Kra, O., Yao, H. and Kadjo, K.N. (2011) Particularités de l'insuffisance rénale chronique chez des patients adultes noirs hospitalisés dans le service de médecine interne du CHU de Treichville. Néphrologie \& Thérapeutique, 7, 531-534. https://doi.org/10.1016/j.nephro.2011.03.009 